RAD Conference Proceedings, vol. 3, pp. 127-131, 2018

ISSN 2466-4626 (online) | DOI: 10.21175/RadProc.2018.28

www.rad-proceedings.org

\title{
DETERMINATION OF STRUCTURAL AND PHOTOELECTRIC CHARACTERISTICS OF ZnO POLYCRYSTALLINE THIN FILMS AND ZnO NANOROD ARRAYS OBTAINED BY SPRAY PYROLYSIS
}

\author{
Atanas Tanushevski1 ${ }^{*}$, Maja Lazarova², Ivan Boev² \\ ${ }^{1}$ Institute of Physics, Faculty of Natural Sciences and Mathematics, University "Sts. Cyril and Methodius”, Skopje, \\ Macedonia \\ ${ }^{2}$ Faculty of Natural and Technical Sciences, “Goce Delcev” University, Stip, Macedonia
}

\begin{abstract}
ZnO}$ polycrystalline thin films and $\mathrm{ZnO}$ nanorod arrays were obtained by the spray pyrolysis method at a substrate temperature of $450{ }^{\circ} \mathrm{C} . \mathrm{By}$ analyzing the XRD diffractograms, the hexagonal crystal structure of the $\mathrm{ZnO}$ films and $\mathrm{ZnO}$ nanorods was determined. On the other hand, the grain size of the films and nanorods was determined using the Debye-Scherrer equation. The optical properties of the films and nanorods were determined by measuring the dependence of the transmission on the wavelength of the light. Also, the optical band gap of $3.28 \mathrm{eV}$ for the ZnO films and $3.21 \mathrm{eV}$ for the $\mathrm{ZnO}$ nanorods was estimated. The photoconductivity spectrum of thin films and nanorods was recorded in the visible light range and their photoconductivity was studied when they were illuminated by $X$-rays, where the incident $X$-rays increase the conductivity of thin films of nanorods. The surface morphologies of the $\mathrm{ZnO}$ films and the $\mathrm{ZnO}$ nanorods, as well as the grain size of the film and the dimensions of the nanorods, were studied by a scanning electron microscope.
\end{abstract}

Key words: Zinc oxide, optical band gap, photoconductivity, surface morphology

\section{INTRODUCTION}

Zinc oxide is a semiconductor with a band gap of $3.3 \mathrm{eV}$ which is used as a transparent conductive film in solar cells and flat screens, gas sensor, ultraviolet light laser, transistors for various applications, photoconductive devices and radiation detectors [1]. The photoconductivity of $\mathrm{ZnO}$ leads to an increase in the number of charge carriers but, under certain conditions, chemical absorption and desorption of molecules may also occur [2]. However, the morphology of $\mathrm{ZnO}$ thin films could be different. Namely, the $\mathrm{ZnO}$ film could be found in polycrystalline form [3] with different grain sizes, in the form of nanowires [1] or in the form of nanorods [4]. In addition, the nanocrystals in the form of assembled nanorods are of particular importance due to the charge transfer in a designated direction, and the reduction of charge carrier recombination [5].

The semiconductor X-radiation detectors are used in material characterization devices, monitoring of nuclear reactions, determining the radiation from medical nuclear devices and radiation detectors [6]. Therefore, semiconductors with a wide forbidden zone are used, such as $\mathrm{GaN}[7]$ and $\mathrm{ZnO}[6,8]$, which change the conductivity depending on the intensity and the wavelength of X-radiation.
Zinc oxide thin films are obtained by various methods such as chemical deposition [9, 10], magnetron sputtering [11], electrodeposition [12], spray pyrolysis $[4,13]$, metal organic chemical vapor deposition [1] and other [6]. For making $\mathrm{ZnO}$ thin films and $\mathrm{ZnO}$ nanorod array films, the method of spray pyrolysis of aqueous solution with various precursors is being used, since the method is simple and economical $[4,13]$. In this paper, we study the spectral photoconductivity of $\mathrm{ZnO}$ thin films and $\mathrm{ZnO}$ films of nanorods arrays, as well as the conductivity of films while being irradiated with X-rays.

\section{MATERIALS AND METHODS}

Thin films of $\mathrm{ZnO}$ were obtained by the spray pyrolysis method of $0.2 \mathrm{M} \mathrm{Zn}\left(\mathrm{CH}_{3} \mathrm{COO}\right)_{2}$ aqueous solution, on glass substrates heated at temperature of $450{ }^{\circ} \mathrm{C}$, whereas the films were polycrystalline. In addition, the thin film of $\mathrm{ZnO}$ nanorods array was obtained by spray pyrolysis of $0.2 \mathrm{M} \mathrm{ZnCl}_{2}$ aqueous solution on glass substrates, which were heated to the same temperature. The air was used as the carrier gas, and the spraying was continuous. To measure the conductivity of the $\mathrm{ZnO}$ thin films, they were deposited on glass slides previously covered with a transparent and conductive $\mathrm{SnO}_{2}$ thin film with a resistance of $10 \Omega / \mathrm{cm}^{2}[14]$. The $\mathrm{SnO}_{2}$ thin film was scratched from

*atanastanush@gmail.com 
A. Tanushevski et al., ZnO polycrystalline and $\mathrm{ZnO}$ nanorods arrays films, RAD Conf. Proc., vol. 3, 2018, 127-131

the glass substrates in a form of a narrow line with a diamond blade. A $\mathrm{ZnO}$ thin film was deposited on that line and, because of its small width, its resistance was reduced.

The crystalline structure of the $\mathrm{ZnO}$ films was determined by the X-ray diffraction pattern obtained using the Rigaku Ultima IV powder X-ray diffractometer when measuring the intensity of X-ray diffraction for $2 \theta$ in the range of $20^{\circ}-70^{\circ}$. Cu- $\mathrm{K}_{a}$ source of X-ray radiation with $\lambda=0.15418 \mathrm{~nm}$ was used, operating at $40 \mathrm{kV}$ anode voltage, current of $40 \mathrm{~mA}$ and a scan rate of $2 \% \mathrm{~min}$. The optical properties of $\mathrm{ZnO}$ films were studied by measuring the dependence of transmission on wavelength in the range of 350-900 $\mathrm{nm}$ using the Varian Cary 50 spectrophotometer. Also, the structure and morphology of $\mathrm{ZnO}$ films was studied by scanning electron microscope VEGA3 LMU. For this purpose, the samples were cut and fastened to the carrier using double-sided adhesive carbon tape. Then, gold was deposited on them with magnetron sputtering on the side of the film. The samples were analyzed with a SE detector at a voltage of $20 \mathrm{kV}$ and a vacuum of 0.018 Pa.

The photoconductivity spectrum of the films was recorded using the HP $34401 \mathrm{~A}$ multimeter, also the monochromatic light of a Beckman DU-2 spectrophotometer was used as a light source with a precisely determined wavelength. Further, the film resistance was measured during darkness and ten seconds after its irradiation with polychromatic X-ray radiation, obtained from the Fe-anode of the JEOL JDX 7 E X-ray diffractometer, at voltages of $30 \mathrm{kV}$ and $40 \mathrm{kV}$ and constant current of $30 \mathrm{~mA}$. The absorbed dose of polychromatic X-ray radiation was measured with the AT1117M Radiation Monitor PU.

\section{RESULTS AND DisCUSSION}

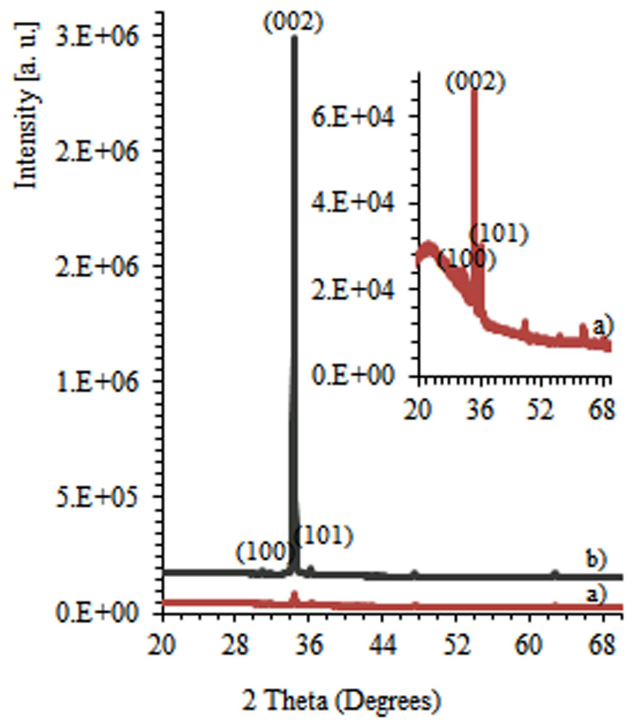

Figure 1. X-ray diffraction pattern of: a) $\mathrm{ZnO}$ films obtained by spray pyrolysis of $\mathrm{Zn}\left(\mathrm{CH}_{3} \mathrm{COO}\right)_{2}$ aqueous solution and b) $\mathrm{ZnO}$ films obtained by spray pyrolysis of $\mathrm{ZnCl}_{2}$ aqueous solution
The XRD patterns of ZnO films obtained by spray pyrolysis of $\mathrm{Zn}\left(\mathrm{CH}_{3} \mathrm{COO}\right)_{2}$ aqueous solution showed a hexagonal wurtzite structure with an expressive peak due to reflection from plane (002), with c-axis preferred orientation, and smaller peaks that refer to planes (100) and (101) (Figure 1) $[15,16]$.

The sharp peaks show the polycrystalline structure of the $\mathrm{ZnO}$ film, but an observed hump in the X-ray diffraction pattern may indicate the presence of an amorphous phase in the $\mathrm{ZnO}$ film. On the other hand, films obtained by spray pyrolysis of $\mathrm{ZnCl}_{2}$ aqueous solution showed a much larger peak at $2 \theta=34.38^{\circ}$, relative to films obtained by spray pyrolysis of $\mathrm{Zn}\left(\mathrm{CH}_{3} \mathrm{COO}\right)_{2}$ aqueous solution, because of the reflection from plane (002) (Figure 1) [1]. This means that the films had different morphologies, despite the fact that they had the same crystal structure. The average grain size was determined from the DebyeScherrer equation [2]:

$$
D=\frac{0.9 \cdot \lambda}{\beta \cdot \cos \theta}
$$

where $\lambda$ is the wavelength of the X-ray source, $\beta$ is the full-width at half-maximum (FWHM) of the diffraction peaks and $\theta$ is the Bragg's angle. By applying the Debye-Scherrer equation, the grain size was calculated to be $40 \mathrm{~nm}$ for $\mathrm{ZnO}$ films obtained by spray pyrolysis of $\mathrm{Zn}\left(\mathrm{CH}_{3} \mathrm{COO}\right)_{2}$ aqueous solution. However, for $\mathrm{ZnO}$ films obtained by spray pyrolysis of $\mathrm{ZnCl}_{2}$ aqueous solution, the grain size was calculated to be $56 \mathrm{~nm}$.

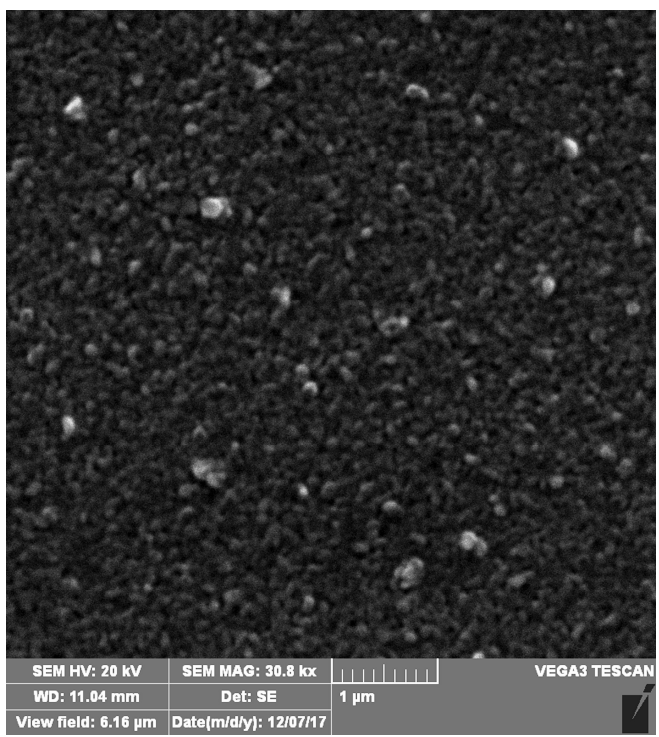

Figure 2. SEM image of the $\mathrm{ZnO}$ polycrystalline films

The morphology of films obtained by spray pyrolysis of $\mathrm{Zn}\left(\mathrm{CH}_{3} \mathrm{COO}\right)_{2}$ aqueous solution shows (Figure 2) that the films are polycrystalline [17]-[19], without the presence of holes. However, the films obtained by spray pyrolysis of $\mathrm{ZnCl}_{2}$ aqueous solution demonstrate (Figure 3) strong-oriented $\mathrm{ZnO}$ nanorods with a maximum diameter of $500 \mathrm{~nm}$ and length of $1 \mu \mathrm{m}$. $\mathrm{ZnO}$ nanorod arrays are grown in the form of vertical columns relative to the surface of the 
A. Tanushevski et al., $\mathrm{ZnO}$ polycrystalline and $\mathrm{ZnO}$ nanorods arrays films..., RAD Conf. Proc., vol. 3, 2018, 127-131

substrates, and are oriented in the direction of the caxis. The interface includes nanorod arrays with a diameter of $500 \mathrm{~nm}$ or it is filled with nanorods with a smaller diameter and, in some places, there are none. However, the density of the nanorods depends on the density of $\mathrm{ZnO}$ seeds and the temperature of the substrates [10].

It is obvious that the differences of grain size determined by the Debye-Scherrer equation and SEM image are due to the limited Debye-Scherrer equation. Namely, Debye-Scherrer equation exists for nano-scale particles, and cannot be used for large grains [20]. This means that many factors could contribute to the width of a diffraction peak, such as crystallite size, microstrain and instrumental broadening [21].

The optical properties of the $\mathrm{ZnO}$ polycrystalline thin film and the thin film of $\mathrm{ZnO}$ nanorod array were studied by recording the spectrum of transmission (Figure 4). The $\mathrm{ZnO}$ polycrystalline films show a change in the light transmission for wavelength of 380 $\mathrm{nm}$, indicating that the film has a defined crystal structure. However, the transmission of the $\mathrm{ZnO}$ nanorod array thin films begins to gradually increase for wavelength of the light of $380 \mathrm{~nm}$, which could be attributed to the light scattering from the nanorods. In order to determine the bandwidth of the forbidden zone, the absorption coefficient is calculated from the following equation [3]:

$$
\alpha=\frac{1}{d} \ln \left(\frac{1}{T}\right)
$$

where $T$ is the transmittance and $d$ is the thickness of the film.

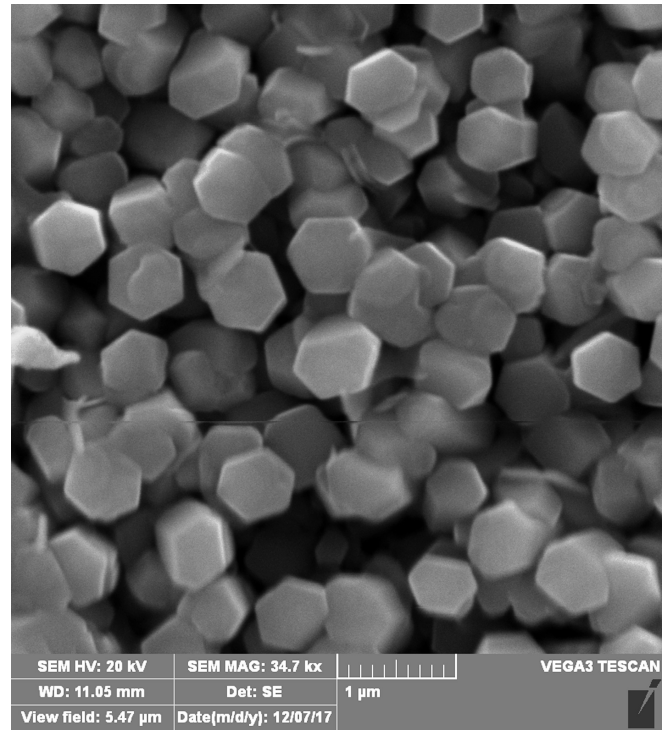

Figure 3. SEM image of the $\mathrm{ZnO}$ nanorod array films

In addition, the bandwidth of the forbidden zone and the character of the electronic transitions are determined by the graphical presentation of $(\alpha h v)^{2}=\mathrm{f}$ $(h v)$, from the cross-section of the linear part of the curve and the $\mathrm{x}$-axis (Figure 5). From the graphs given in Figure 5, the band gap is valued to be $3.21 \mathrm{eV}$ for polycrystalline $\mathrm{ZnO}$ films and $3.28 \mathrm{eV}$ for $\mathrm{ZnO}$ nanorod array film.

The photoconductivity of $\mathrm{ZnO}$ films was examined in the presence of UV light illumination, due to the chemisorption/desorption of oxygen on the surface of the $\mathrm{ZnO}$ film [1]. Namely, in dark conditions, the oxygen is absorbed on the surface of the $\mathrm{ZnO}$ film by capturing the electrons from the films, decreasing the conductivity of the $\mathrm{ZnO}$ film. While being illuminated by light, pairs of electron-holes are generated, where the holes interact with the oxygen which is then released from the surface of the film, given by the equation:

$$
\mathrm{O}_{2(\mathrm{ad})}^{-}+h^{+} \rightarrow \mathrm{O}_{2(\mathrm{~g})}
$$

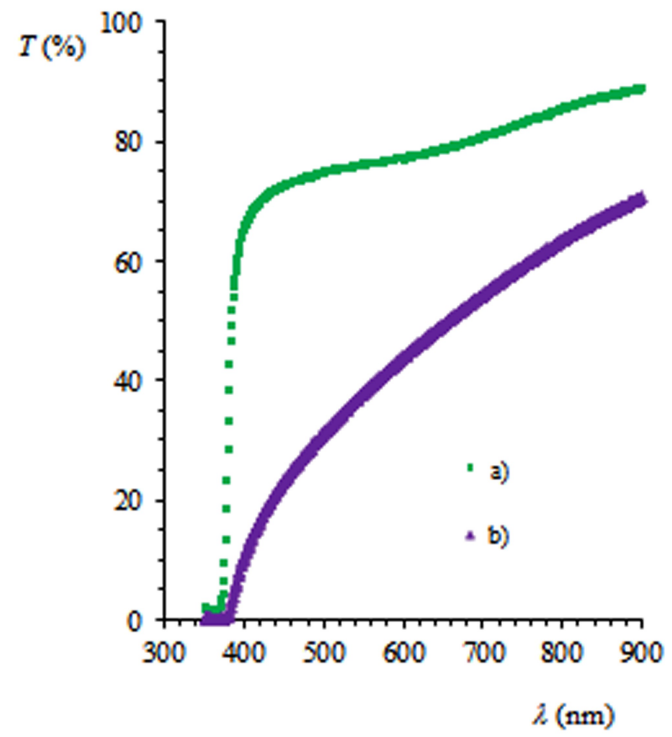

Figure 4. Transmission optical spectra of: a) $\mathrm{ZnO}$ polycrystalline films and b) $\mathrm{ZnO}$ nanorod array films

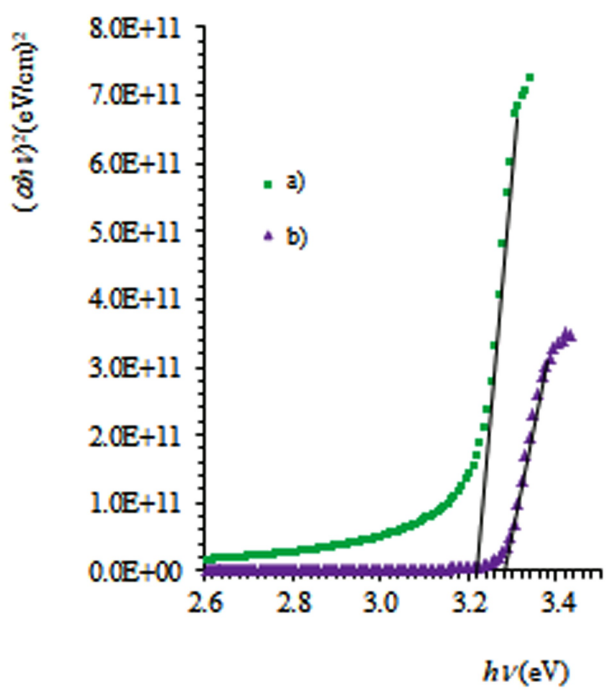

Figure 5. Plot of ( $\alpha h v) 2$ versus photon energy of: a) $\mathrm{ZnO}$ polycrystalline films and b) $\mathrm{ZnO}$ nanorod array films 
A. Tanushevski et al., ZnO polycrystalline and $\mathrm{ZnO}$ nanorods arrays films, RAD Conf. Proc., vol. 3, 2018, 127-131

On the other hand, photogenerated electrons remain in the film and lead to increasing conductivity of the $\mathrm{ZnO}$ film. Figure 6 shows the dependence of the photoconductivity of the polycrystalline $\mathrm{ZnO}$ film on the energy of photons, where the maximum photoconductivity matches the photon energy of $3.36 \mathrm{eV}$, and $3.27 \mathrm{eV}$ for the $\mathrm{ZnO}$ nanorod array film. If they are considered to be a direct semiconductor according to the electron transfer, then the band gap could be determined from the photon energy values at maximum photoconductivity. The band gap of a polycrystalline $\mathrm{ZnO}$ film determined from the photoconductivity differs from the band gap determined by the transmission spectrum. This may be as a result of a change in the conductivity of the film due to the effect of chemical adsorption and desorption of oxygen by the polycrystalline $\mathrm{ZnO}$ film.

In addition, the electrical resistance of the films was studied during their irradiation with polychromatic $\mathrm{X}$-ray radiation produced in the X-ray tube with Fe-anode. The absorbed dose of $5.9 \mu \mathrm{R} / \mathrm{h}$ was measured for polychromatic X-ray radiation at $30 \mathrm{kV}$ voltage, as well as the absorbed dose of $48 \mathrm{mR} / \mathrm{h}$ at $40 \mathrm{kV}$ voltage. The intensity and the energy spectrum of $\mathrm{X}$-ray radiation depends on the applied voltage and current, where the energy of X-ray radiation increases with the voltage of X-ray tube. Additionally, the X-ray absorption spectrum of $\mathrm{ZnO}$ depends on their mass attenuation coefficient and the energy of X-ray radiation [22].

The $R=444 \mathrm{k} \Omega$ resistance of the polycrystalline $\mathrm{ZnO}$ film in dark conditions was determined. While, the resistance $R=1.096 \mathrm{M} \Omega$ under X-ray irradiation was measured at $30 \mathrm{kV}$ anode voltage of the X-ray tube; at the anode voltage of $40 \mathrm{kV}$, the resistance had the value of $R=1.160 \mathrm{M} \Omega$. Also, the resistance $R=300$ $\mathrm{k} \Omega$ for the $\mathrm{ZnO}$ nanorod array film was measured in dark conditions, whereas $R=279 \mathrm{k} \Omega$ and $R=250 \mathrm{k} \Omega$ under X-ray irradiation were obtained at $30 \mathrm{kV}$ and 40 $\mathrm{kV}$ anode voltage, respectively.

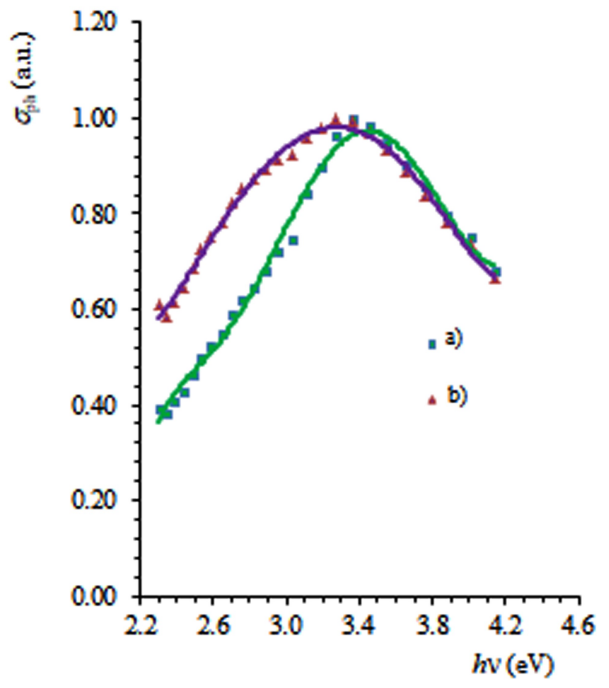

Figure 6. Photoconductivity spectra versus photon energy of: a) $\mathrm{ZnO}$ polycrystalline films and b) $\mathrm{ZnO}$ nanorod array films
The X-ray irradiation of the polycrystalline $\mathrm{ZnO}$ film contributes to the reduction of its conductivity, while the conductivity of the $\mathrm{ZnO}$ nanorod array film increases. This could be due to the difference in the adsorption/desorption rate of the oxygen and the number of generated electron-holes pairs, in the polycrystalline $\mathrm{ZnO}$ film and on the $\mathrm{ZnO}$ nanorod array film during their irradiation with $\mathrm{X}$-rays.

The performed X-ray irradiation on the $\mathrm{ZnO}$ polycrystalline film helps the release of oxygen from grains, as well as the adsorption of oxygen at the grain boundaries. By taking into account the presence of an amorphous phase in the polycrystalline film, shown in the X-ray diffraction pattern, the conductivity would reduce due to the released oxygen which is then captured at the grain boundaries [23] and decreases over time. On the other hand, the X-ray irradiation on $\mathrm{ZnO}$ nanorod array film promotes the release of oxygen, thus creating $\mathrm{Zn}$ atoms with dangling bonds [24] which would, in this case, increase the conductivity over time [1].

\section{CONCLUSION}

Zinc oxide thin polycrystalline films and $\mathrm{ZnO}$ nanorod array films were obtained by spray pyrolysis of $\mathrm{Zn}\left(\mathrm{CH}_{3} \mathrm{COO}\right)_{2}$ aqueous solution and by spray pyrolysis of $\mathrm{ZnCl}_{2}$ aqueous solution, respectively. The $\mathrm{ZnO}$ films show hexagonal wurtzite structure with an expressive peak that is due to reflection from the lattice plane (002). The optical band gap of $3.21 \mathrm{eV}$ of polycrystalline $\mathrm{ZnO}$ films and $3.28 \mathrm{eV}$ of $\mathrm{ZnO}$ nanorod array films were determined. Further, by using the photoconductivity, the bandwidth of the forbidden zone of polycrystalline $\mathrm{ZnO}$ films valued $3.36 \mathrm{eV}$ and $3.27 \mathrm{eV}$ for $\mathrm{ZnO}$ nanorod array films were determined. In addition, the conductivity of the films was studied under polychromatic X-radiation, at $30 \mathrm{kV}$ and $40 \mathrm{kV}$ anode voltage of the $\mathrm{X}$-ray tube. The $\mathrm{X}$-ray irradiation of the polycrystalline $\mathrm{ZnO}$ film contributes to the reduction of its conductivity, while the conductivity of the $\mathrm{ZnO}$ nanorod array film increases. Likely, there is a difference in the mechanism of conductivity of the $\mathrm{ZnO}$ polycrystalline film and the $\mathrm{ZnO}$ nanorod array film in case of UV light illumination and X-ray irradiation, as well as in the effect of the generated electron-hole pairs in the conductivity mechanism.

\section{REFERENCES}

1. D. Park, K. Yong, "Photoconductivity of vertically aligned ZnO nanoneedle array,” J. Vac. Sci. Technol. $B$ Nanotechnol. Microelectron., vol. 26, no. 6 , pp. 1933 - 1936, Nov. 2008. DOI: $10.1116 / 1.2998730$

2. S. K. Mishra, R. K. Srivastava, S. G. Prakash, "ZnO nanoparticles: Structural, optical and photoconductivity characteristics", J. Alloys Compd., vol. 539, no. 25, pp. $1-6$, Oct. 2012. DOI: 10.1016/j.jallcom.2012.06.024

3. S. T. Tan et al., "Properties of polycrystalline $\mathrm{ZnO}$ thin films by metal organic chemical vapor deposition", J. Cryst. Growth, vol. 281, no. 2-4, pp. 571 - 576, Aug. 2005.

DOI: 10.1016/j.jcrysgro.2005.04.093 
A. Tanushevski et al., $\mathrm{ZnO}$ polycrystalline and $\mathrm{ZnO}$ nanorods arrays films..., RAD Conf. Proc., vol. 3, 2018, 127-131

4. T. Dedova, O. Volobujeva, J. Klauson, A. Mere, M. Krunks, "ZnO Nanorods via Spray Deposition of Solutions Containing Zinc Chloride and Thiocarbamide", Nanoscale Res. Lett., vol. 2, no. 8, pp. $391-396$, Jul. 2007.

DOI: $10.1007 / \mathrm{s} 11671-007-9072-6$

PMid: 21794191

PMCid: PMC3246384

5. Y. Bu, Z. Chen, W. Li, J. Yu, "High-Efficiency Photoelectrochemical Properties by a Highly Crystalline CdS-Sensitized ZnO Nanorod Array", ACS Appl. Mater. Interfaces, vol. 5, no. 11, pp. 5097 - 5104, Jun. 2013. DOI: $10.1021 / \mathrm{am} 400964 \mathrm{c}$ PMid: 23688263

6. X. Zhao et al., "Nanosecond X-ray detector based on high resistivity $\mathrm{ZnO}$ single crystal semiconductor", Appl. Phys. Lett., vol. 108, no. 17, 171103, Apr. 2016. DOI: $10.1063 / 1.4947085$

7. J.Y. Duboz, "GaN for x-ray detection", Appl. Phys. Lett., vol. 92, no. 26, 263501, Jun. 2008.

DOI: $10.1063 / 1.2951619$

8. $\mathrm{H}$. Endo, "Fabrication and characterization of a $\mathrm{ZnO}$ $\mathrm{X}$-ray sensor using a high-resistivity $\mathrm{ZnO}$ single crystal grown by the hydro thermal method", Nucl. Instrum. Methods Phys. Res. A, vol. 665, pp. 15-18, Feb. 2011. DOI: 10.1016/j.nima.2011.11.009

9. T. H. Lee; H. J. Sue, X. Cheng, "Solid-state dyesensitized solar cells based on $\mathrm{ZnO}$ nanoparticle and nanorod array hybrid Photoanodes”, Nanoscale Res. Lett., vol. 6, no. 517, pp. $1-8$, Sep. 2011. DOI: $10.1186 / 1556-276 \mathrm{X}-6-517$

10. M. J. Jin, "Low-Temperature Solution-Based Growth of $\mathrm{ZnO}$ Nanorods and Thin Films on Si Substrates", J. Nanosci. Nanotechnol., vol. 9, no. 12, pp. 1 - 4, Dec. 2009. DOI: $10.1166 /$ jnn.2009.1762

11. A. Tanuševski, V. Georgieva, "Optical and electrical properties of nanocrystal zinc oxide films prepared by dc magnetron sputtering at different sputtering pressures", Appl. Surf. Sci., vol. 256, no. 16, pp. 5056 - 5060, Jun. 2010. DOI: 10.1016/j.apsusc.2010.03.059

12. A. K. Ylldırım, B. Altıokka, "Effect of Potential on Structural, Morphological and Optical Properties of $\mathrm{ZnO}$ Thin Films Obtained by Electrodeposition", J. Mater. Sci. Eng. B, vol. 5, no. 3-4, pp. 107 - 112, Apr. 2015.

DOI: $10.17265 / 2161-6221 / 2015 \cdot 3-4.001$

13. N. Memarian et al., "Hierarchically Assembled $\mathrm{ZnO}$ Nanocrystallites for High-Efficiency Dye-Sensitized Solar Cells", Angew. Chem. Int. Ed., vol. 50, no. 51, pp. $12321-12325$, Dec. 2011 DOI: 10.1002/anie.201104605

14. B. Thangaraju, "Structural and electrical studies on highly conducting spray deposited fluorine and antimony doped $\mathrm{SnO}_{2}$ thin films from $\mathrm{SnCl}_{2}$ precursor", Thin Solid Films, vol. 402, no. 1-2, pp. $71-78$, Jan. 2002.

DOI: 10.1016/So040-6090(01)01667-4
15. A. Abdolahzadeh Ziabari, F.E.Ghodsi, "Optoelectronic studies of sol-gel derived nanostructured $\mathrm{CdO}-\mathrm{ZnO}$ composite films", Journal of Alloys and Compounds, vol. 509, no 35, pp. 8748-8755, Sep. 2011. DOI: 10.1016j.jallcom.2011.06.050

16. A.M.M.Tanveer Karim, M.K.R.Khan, M.Mozibur Rahman, "Effect of $\mathrm{Zn} / \mathrm{Cd}$ ratio on the optical constants and photoconductive gain of $\mathrm{ZnO}-\mathrm{CdO}$ crystalline thin films", Materials Science in Semiconductor Processing, vol. 41, pp. 184-192, Jan. 2016. DOI: 10.1016/j.mssp.2015.08.037

17. Ayça Kıyak Yıldırım, Barıs Altıokka, "Effects of concentration on $\mathrm{CdO}$ films grown by electrodeposition", Applied Nanoscience, vol. 7, no. 3-4, pp. 131-135, Apr. 2017. DOI: $10.1007 / \mathrm{s} 13204-017-0552-4$

18. Ayça Kıyak Yıldırım, Barıs Altıokka, "An investigation of effects of bath temperature on CdO films prepared by electrodeposition", Applied Nanoscience, vol. 7, no. 8, pp. 513-518. , Nov. 2017. DOI: $10.1007 / \mathrm{s} 13204-017-0591-\mathrm{x}$

19. Barıs Altıokka, Ayça Kıyak Yıldırım, "Effects of pH on CdO films deposited onto ITO coated glass substrates by electrodeposition", International Journal of Surface Science and Engineering, vol. 12, no. 1, pp. 13, Jan. 2018. DOI: 10.1504/IJSURFSE.2018.090052

20. R. Saravanan, M. Prema Rani, "Metal and Alloy Bonding: An Experimental Analysis Charge Density in Metals and Alloys",Springer, ch. 1, pp. 25-26, Sep. 2011. DOI 10.1007/978-1-4471-2204-3

21. H.A. Wahab, A.A. Salama, A.A. El-Saeid, O. Nur M. Willander, I.K. Battisha, "Optical, structural and morphological studies of ( $\mathrm{ZnO})$ nano-rod thin films for biosensor applications using sol gel technique”, Results in Physics, vol. 3, pp. 46-51, Dec. 2013. DOI: 10.1016/j.rinp.2013.01.005

22. J. Haug, A. Chassé, M. Dubiel, Ch. Eisenschmidt, M. Khalid, and P. Esquinazi, "Characterization of lattice defects by $\mathrm{x}$-ray absorption spectroscopy at the $\mathrm{Zn}$ K-edge in ferromagnetic, pure $\mathrm{ZnO}$ films", J. Appl. Phys, vol. 110, no. 063507, pp. 1-11, Sep. 2011 DOI: $10.1063 / 1.3631774$

23. R. Gurwitz, R. Cohen, I. Shalish, "Interaction of light with the $\mathrm{ZnO}$ surface: Photon induced oxygen "breathing," oxygen vacancies, persistent photoconductivity, and persistent photovoltage," J. Appl. Phys., vol. 115, no. 3, 033701, Jan. 2014. DOI: $10.1063 / 1.4861413$

24. Th. J. Penfold et al., "Revealing hole trapping in zinc oxide nanoparticles by time-resolved X-ray spectroscopy", Nat. Commun., vol.1, no.478. pp. 9, Dec. 2018.

DOI: 10.1038/s41467-018-02870-4 